\title{
On Some Well Known Fixed Point Theorems in $b$-Metric Spaces
}

\author{
Mehmet Kir ${ }^{*}$, Hükmi Kiziltunc \\ Department of Mathematics, Faculty of Science, Ataturk University, Erzurum-Turkey \\ *Corresponding author: mehmetkir04@gmail.com
}

Received August 14, 2013; Revised September 17, 2013; Accepted September 25, 2013

\begin{abstract}
In this paper, our purpose is to show that Kannan Type and Chatterjea type contractive mappings have unique fixed point in b-metric spaces. Also, we see surprisingly a way that contrary to the known (usual) metric spaces, any contraction mapping is not need to be a weak conraction mapping in b-metric spaces.
\end{abstract}

Keywords: fixed point, b-metric spaces, contraction mappings

Cite This Article: Mehmet Kir, and Hükmi Kiziltunc, "On Some Well Known Fixed Point Theorems in $b$ Metric Spaces.” Turkish Journal of Analysis and Number Theory 1, no. 1 (2013): 13-16. doi: 10.12691/tjant-1-1-4.

\section{Introduction and Prelimnaries}

Fixed point theory is one of the most important topic in development of nonlinear analysis. Also, fixed point theory has been used effectively in many other branch of science, such as chemistry, biology, economics, computer science, engineering, and many others.

It is well known that Banach's contraction mapping theorem is one of the pivotal results of functional analysis. A mapping $T: X \rightarrow X$ where $(\mathrm{X}, \mathrm{d})$ is a metric space, is said to be a contraction if there exists $k \in[0,1)$ such that for all $x, y \in X$;

$$
d(T x, T y) \leq k d(x, y)
$$

If the metric space $(\mathrm{X}, \mathrm{d})$ is complete then the mapping satisfying (1.1) has a unique fixed point. Inequality (1.1) implies continuity of T. A natural question is that whether we can find contractive conditions which will imply existence of fixed point in a complete metric space but will not imply continuity.

Kannan in [2] established the following result in which the above question has been answered in the affirmative.

If $T: X \rightarrow X$ where $(\mathrm{X}, \mathrm{d})$ is a complete metric space, satisfies the inequality

$$
d(T x, T y) \leq a[d(x, T x)+d(y, T y)]
$$

where $a \in\left[0, \frac{1}{2}\right)$ and $x, y \in X$ then $\mathrm{T}$ has a unique fixed point. The mappings satisfying (1.2) are called Kannan type mappings.

A similar contractive condition has been introduced by Chatterjea [3] as following.

If $T: X \rightarrow X$ where $(\mathrm{X}, \mathrm{d})$ is a complete metric space, satisfies the inequality

$$
d(T x, T y) \leq b[d(x, T y)+d(y, T x)]
$$

where $b \in\left[0, \frac{1}{2}\right)$ and $x, y \in X$ then $\mathrm{T}$ has a unique fixed point. The mappings satisfying (1.3) are called Chatterjea type mappings.

Some problems, particularly the problem of the convergence of measurable functions with respect to a measure, lead to a generalization of notation of metric. Using this idea, Czerwik in [4] and [5] presented a generalization of the well known Banach's fixed point theorem in so called $b$-metric spaces.

Our purpose is to show that some well-known fixed point theorems are valid in $b$-metric spaces. It is interesting that we see some properties in (usual) metric space is not valid in $b$-metric space.

Definition 1. [7] Let $X$ be a nonempty set and let $s \geq 1$ be a given real number. A function $d: X \times X \rightarrow \mathbb{R}_{+}$is called a b-metric provided that, for all $x, y, z \in X$,

1. $d(x, y)=0$ if and only if $x=y$,

2. $d(x, y)=d(y, x)$,

3. $d(x, z) \leq s[d(x, y)+d(y, z)]$,

A pair $(X, d)$ is called a b-metric space.

It is clear that the definiton of $b$-metric space is a extension of usual metric space. Also, if we consider $\mathrm{s}=1$ in Definition 1, then we obtain definition of usual metric space. By this reason, our results are more general than the same results in (usual) metric space.

We can give some example of $b$-metric space as following:

Example 1. [6] The space $l_{p}(0<p<1)$,

$$
l_{p}=\left\{\left(x_{n}\right) \subset \mathbb{R}: \sum_{n=1}^{\infty}\left|x_{n}\right|^{p}<\infty\right\},
$$

together with the function $d: l_{p} \times l_{p} \rightarrow \mathbb{R}$

$$
d(x, y)=\left(\sum_{n=1}^{\infty}\left|x_{n}-y_{n}\right|^{p}\right)^{\frac{1}{p}}
$$


where $x=x_{n} ; y=y_{n} \in l_{p}$ is a b-metric space. By an elementary calculation we obtain that

$$
d(x, z) \leq 2^{\frac{1}{p}}[d(x, y)+d(y, z)]
$$

Example 2. [6] The space $L_{p}(0<p<1)$ of all real functions $x(t), t \in[0,1]$ such that

$$
\int_{0}^{1}|x(t)|^{p} d t<\infty
$$

is b-metric space if we take

$$
d(x, y)=\left(\int_{0}^{1}|x(t)-y(t)|^{p} d t\right)^{\frac{1}{p}}
$$

for each $x, y \in L_{p}$,

Remark 1. Note that a (usual) metric space is evidently a b-metric space. However, Czerwik [4,5] has shown that a $b$-metric on $X$ need not be a metric on $X$.

Now, we illüstrate Remark 1 as follows:

Example 3. [7] Let $X=\{0,1,2\}$ and $d(2,0)=d(0 ; 2)=$ $m \geq 2, d(01)=d(1,2)=d(0,1)=d(2,1)=1$ and $d(0$, $0)=d(1,1)=d(2,2)=0$. Then,

$$
d(x, y) \leq \frac{m}{2}[d(x, z)+d(z, y)]
$$

for all $x, y, z \in X$. If $m>2$, the ordinary triangle inequality does not hold.

We continue by presenting definition of Cauchy sequence, convergent sequence and complete $b$-metric space.

Definition 2. [6] Let $(X, d)$ be a b-metric space. Then a sequence $\left(x_{n}\right)$ in $X$ is called Cauchy sequence if and only if for all $\varepsilon>0$ there exists $n(\varepsilon) \in \mathbb{N}$ such that for each $n, m \geq n(\varepsilon)$ we have $d\left(x_{n}, x_{m}\right)<\varepsilon$.

Definition 3. [6] Let $(X, d)$ be a b-metric space. Then a sequence $\left(x_{n}\right)$ in $X$ is called convergent sequence if and only if there exists $x \in X$ such that for all there exists $n(\varepsilon) \in \mathbb{N}$ such that for all $n \geq n(\varepsilon)$ we have $d\left(x_{n}, x\right)<\varepsilon$. In this case we write $\lim _{n \rightarrow \infty} x_{n}=x$.

Definition 4. [6] The b-metric space is complete if every Cauchy sequence convergent.

Definition 5. [8] Let $E$ be a nonempty set and $T: E \rightarrow E$ a selfmap. We say that $x \in E$ is a fixed point of $T$ if $T(x)$ $=x$ and denote by FT or Fix (T) the set of all fixed points of $T$.

Let $E$ be any set and $T: E \rightarrow E$ a selfmap. For any given $x \in E$, we define $T^{n}(x)$ inductively by $T^{0}(x)=x$ and $T^{n+1}(x)=T\left(T^{n}(x)\right)$; we recall $T_{n}(x)$ the nth iterative of $x$ under $T$.

For any $x_{0} \in X$, the sequence $\left\{x_{n}\right\}_{n \geq 0} \subset X$ given by

$$
x_{n}=T x_{n-1}=T^{n} x_{0}, \quad n=1,2, \ldots
$$

is called the sequence of successive approximations with the initial value $x_{0}$. It is also known as the Picard iteration starting at $x_{0}$.
Definition 6. [8] Let $(X, d)$ be a metric space. A mapping $T: X \rightarrow X$ is called weak contraction if there exists a constant $\delta \in(0,1)$ and some $L \geq 0$ such that

$$
d(T x, T y) \leq \delta d(x, y)+L d(y, T x)
$$

fall all $x, y \in X$.

Remark 2. [8] Due to the symmetry of the distance, the weak contractive condition (1.5) implicitly includes the following dual one

$$
d(T x, T y) \leq \delta d(x, y)+L d(x, T y)
$$

fall all $x, y \in X$.

Consequently, in order to check the weak contractiveness of $\mathrm{T}$; it is necessary to check both (1.5) and (1.6).

Remark 3. It is clear that any contraction mapping is also weak contraction mapping in a (usual) metric space.

\section{Main Results}

In this section, we give some fixed point theorems arising from $b$-metric spaces. Also, we find an intersting comparison between (usual) metric spaces and $b$-metric spaces. Our first theorem about Banach's contraction princible in $b$-metric spaces.

Theorem 1. Let $(X, d)$ be a complete b-metric space with constant $s \geq 1$ and define the sequence $\left\{x_{n}\right\}_{n=1}^{\infty} \subset X$ by the recursion (1.4). Let $T: X \rightarrow X$ be a contraction with the restrictions $k \in[0.1)$ and $k s<1$. Then, there exists $x^{*} \in X$ such that $x_{n} \rightarrow x^{*}$ and $x^{*}$ is unique fixed point of $T$.

Proof. Let $x_{0} \in X$ and $\left\{x_{n}\right\}_{n=1}^{\infty}$ be a sequence in $X$ defined as following

$$
x_{n}=T x_{n-1}=T^{n} x_{0}, \quad n=1,2, \ldots
$$

Since $\mathrm{T}$ is a contraction with constant $k \in[0.1)$ then, we obtain

$$
d\left(T^{2} x_{0}, T^{2} x_{1}\right) \leq k d\left(T x_{0}, T x_{1}\right) \leq k^{2} d\left(x_{0}, x_{1}\right)
$$

Continuing this process, we easily arrive at

$$
d\left(T^{2} x_{0}, T^{2} x_{1}\right) \leq k^{n} d\left(x_{0}, x_{1}\right)
$$

Now, we show that $\left\{x_{n}\right\}_{n=1}^{\infty}$ is a Cauchy sequence in $X$. Let $m, n>0$ with $m>n$,

$$
\begin{aligned}
d\left(x_{n}, x_{m}\right)< & s d\left(x_{n}, x_{n+1}\right)+s^{2} d\left(x_{n+1}, x_{n+2}\right) \\
& +s^{3} d\left(x_{n+2}, x_{n+3}\right)+\cdots \\
\leq & s k^{n} d\left(x_{0}, x_{1}\right)+s^{2} k^{n+1} d\left(x_{0}, x_{1}\right) \\
& +s^{3} k^{n+2} d\left(x_{0}, x_{1}\right)+\cdots \\
= & d\left(x_{0}, x_{1}\right) s k^{n}\left[\begin{array}{c}
1+s k+(s k)^{2} \\
+(s k)^{3}+\cdots
\end{array}\right]
\end{aligned}
$$


When we take $n, m \rightarrow \infty$ in (2.3), we arrive at

$$
\lim _{n \rightarrow \infty} d\left(x_{m}, x_{n}\right)=0
$$

Hence, $\left\{x_{n}\right\}_{n=1}^{\infty}$ is a Cauchy sequence in $X$. In view of completeness of $X$; we consider that $\left\{x_{n}\right\}_{n=1}^{\infty}$ convergent to $x^{*} \in X$.

Now, we show that $x^{*}$ is the unique fixed point of $T$. Indeed

$$
T x^{*}=\lim _{n \rightarrow \infty} T x_{n}=\lim _{n \rightarrow \infty} T x_{n+1}=x^{*}
$$

Therefore, $x^{*}$ is a fixed point of $T . T_{o}$ is complete the proof finaly, we have to show that the fixed point is unique. Assume that $x^{\prime}$ is an other fixed point of T. Then, $T x^{\prime}=x^{\prime}$.

$$
d\left(x^{*}, x^{\prime}\right)=d\left(T x^{*}, T x^{\prime}\right) \leq k d\left(x^{*}, x^{\prime}\right)
$$

The (2.4) implies that $k \geq 1$; but this case is a contradiction to $k \in[0.1)$. So the fixed point is unique. This completes the proof.

Our next theorem about Kannan type fixed point theorem in $b$-metric spaces.

Theorem 2. Let $(X, d)$ be a complete b-metric space with constant $s \geq 1$ and define the sequence $\left\{x_{n}\right\}_{n=1}^{\infty} \subset k$ by the recursion (1.4). Let $T: X \rightarrow X$ be a mapping for which there exists $\mu \in\left[0, \frac{1}{2}\right)$ such that

$$
d(T x, T y) \leq \mu[d(x, T x)+d(y, T y)]
$$

for all $x, y \in X$.

Then, there exists $x^{*} \in X$ such that $x_{n} \rightarrow x^{*}$ and $x^{*}$ is unique fixed point of $T$.

Proof. Let $x_{0} \in X$ and $\left\{x_{n}\right\}_{n=1}^{\infty}$ be a sequence in $X$ defined as $x_{n}=T x_{n-1}=T^{n} x_{0}, n=1,2, \cdots$. By using (2.5) and (1.4) we obtain that

$$
\begin{aligned}
& d\left(x_{n}, x_{n+1}\right) \\
& =d\left(T x_{n-1}, T x_{n}\right) \\
& \leq \mu\left[d\left(x_{n-1}, x_{n}\right)+d\left(x_{n}, x_{n+1}\right)\right]
\end{aligned}
$$

and we obtain

$$
d\left(x_{n}, x_{n+1}\right) \leq \frac{\mu}{1-\mu} d\left(x_{n-1}, x_{n}\right)
$$

Similarly, we have

$$
d\left(x_{n}, x_{n+1}\right) \leq\left(\frac{\mu}{1-\mu}\right)^{n} d\left(x_{0}, x_{1}\right)
$$

Note that $\mu \in\left[0, \frac{1}{2}\right)$ then $\frac{\mu}{1-\mu} \in[0,1)$. Thus, $T$ is a contraction mapping. We deduce, in similar manner to that in the proof of Theorem 1 that $\left\{x_{n}\right\}_{n=1}^{\infty}$ is a Cauchy sequence and hence, a convergent sequence, too. We consider that $\left\{x_{n}\right\}_{n=1}^{\infty}$ convergent to $x^{*} \in X$ then we have

$$
\begin{aligned}
d\left(x^{*}, T x^{*}\right) \leq & s\left[d\left(x^{*}, x_{n}\right)+d\left(x_{n}, T x^{*}\right)\right] \\
\leq & s d\left(x^{*}, x_{n}\right) \\
& +s \mu\left[d\left(x_{n-1}, x_{n}\right)+d\left(x_{n}, T x^{*}\right)\right]
\end{aligned}
$$

and we arrive at

$$
d\left(x^{*}, T x^{*}\right) \leq \frac{s}{1-s \mu} d\left(x^{*}, x_{n}\right)+\frac{s \mu}{1-s \mu} d\left(x_{n}, T x^{*}\right) .
$$

Also, thanks to (2.7), we obtain that

$$
\begin{aligned}
d\left(x^{*}, T x^{*}\right) \leq & \frac{s}{1-s \mu} d\left(x^{*}, x_{n}\right) \\
& +\frac{s \mu}{1-s \mu}\left(\frac{\mu}{1-\mu}\right)^{n} d\left(x_{0}, x_{1}\right) .
\end{aligned}
$$

Letting $n \rightarrow \infty$ in (2.9),

$$
\lim _{n \rightarrow \infty} d\left(x^{*}, T x^{*}\right)=0
$$

Therefore, $x^{*}=T x^{*}$ and implies that $x^{*}$ is a fixed point of $T$. It is easy to see the fixed point is unique.

Remark 4. In proof of Theorem 2, it is clear that we have not heard of any restriction to actualize the Kannan's fixed point theorem in b-metric spaces.

Proposition 1. Contrary to the known (usual) metric spaces, any mapping satisfying the contractive condition (2.5) need not be a weak contraction in a b-metric spaces unless under the terms $s \mu \in\left[0, \frac{1}{2}\right)$.

Proof. Let $T: X \rightarrow X$ be a mapping satisfying (2.5), we have

$$
\begin{aligned}
d(T x, T y) & \leq \mu[d(x, T x)+d(y, T y)] \\
& \leq \mu[s d(x, y)+s d(y, T x)+d(x, T y)] \\
& \leq \mu[s d(x, y)+2 s d(y, T x)+s d(x, T y)]
\end{aligned}
$$

and we obtain

$$
d(T x, T y) \leq \frac{s \mu}{1-s \mu} d(x, y)+\frac{2 s \mu}{1-s \mu} d(y, T x) .
$$

According to the inequalty (2.10), $T$ is not a weak contraction unless the terms $\mu s \in\left[0, \frac{1}{2}\right)$

Remark 5. In Theorem 2, we see that a mapping satisfying the contractive condition (2.5) is also a contraction mapping in b-metric space. Also, in Proposition 1, we see that a mapping satisfying the contractive condition (2.5) is not need to be a weak conraction. Consequently, it is interesting that contrary to the known (usual) metric spaces, any contraction mapping is not need to be a weak conraction mapping in b-metric spaces.

Our next theorem is about Chatterjea type fixed point theorem in $b$-metric spaces.

Theorem 3. $(X, d)$ be a complete b-metric space and define the sequence $\left\{x_{n}\right\}_{n=1}^{\infty} \subset X$ by the Recursion (1.4). Let $T: X \rightarrow X$ be a mapping under the terms $s \lambda \in\left[0, \frac{1}{2}\right)$ such that 


$$
d(T x, T y) \leq \lambda[d(x, T Y)+d(y, T X)]
$$

fall all $x, y \in X$.

Then, there exists $x^{*} \in X$ such that $x_{n} \rightarrow x^{*}$ and $x^{*}$ is unique fixed point of $T$.

Proof. Let $x_{0} \in X$ and $\left\{x_{n}\right\}_{n=1}^{\infty}$ be a sequence in $X$ defined as $x_{n}=T x_{n-1}=T^{n} x_{0}, n=1,2, \ldots$ By using (2.11) and (1.4) we obtain that

$$
\begin{aligned}
d\left(x_{n}, x_{n+1}\right) & =d\left(T x_{n-1}, T x_{n}\right) \\
& \leq \lambda\left[d\left(x_{n-1}, T x_{n}\right)+d\left(x_{n}, T x_{n-1}\right)\right] \\
& =\lambda\left[d\left(x_{n-1}, x_{n+1}\right)+d\left(x_{n}, x_{n}\right)\right] \\
& \leq s \lambda\left[d\left(x_{n-1}, x_{n}\right)+d\left(x_{n}, x_{n+1}\right)\right]
\end{aligned}
$$

thus, we have

$$
d\left(x_{n}, x_{n+1}\right) \leq \frac{s \lambda}{1-s \lambda} d\left(x_{n-1}, x_{n}\right)
$$

Note that $s \lambda \in\left[0, \frac{1}{2}\right)$ then $\frac{s \lambda}{1-s \lambda} \in[0.1)$.Thus, $T$ is a contraction mapping. By using similar method in the proof of Theorem 1 and Theorem 2, we see that $\left\{x_{n}\right\}_{n=1}^{\infty}$ is a Cauchy sequence and hence a convergent sequence, too. we consider that $\left\{x_{n}\right\}_{n=1}^{\infty}$ convergent to $x^{*} \in X$.

Now, we show that $x *$ is a fixed point of T. We have

$$
\begin{aligned}
d\left(x^{*}, T x^{*}\right) \leq & s\left[d\left(x^{*}, x_{n+1}\right)+d\left(x_{n+1}, T x^{*}\right)\right] \\
& =s d\left(x^{*}, x_{n+1}\right)+s d\left(T x_{n}, T x^{*}\right) \\
\leq & s d\left(x^{*}, x_{n+1}\right) \\
& +s \lambda\left[d\left(x^{*}, T x_{n}\right)+d\left(x_{n}, T x^{*}\right)\right] .
\end{aligned}
$$

Thus, we obtain that

$$
\begin{aligned}
d\left(x^{*}, T x^{*}\right) \leq & s d\left(x^{*}, x_{n+1}\right) \\
& +s \lambda d\left(x^{*}, x_{n+1}\right)+s \lambda d\left(x_{n}, T x^{*}\right) .
\end{aligned}
$$

Letting $n \rightarrow \infty$ in (2.16),

$$
d\left(x^{*}, T x^{*}\right) \leq s \lambda d\left(x^{*}, T x^{*}\right) .
$$

The inequalty (2.17) is false unless $d\left(x^{*}, T x^{*}\right)=0$. Thus, we arrive at $x^{*}=T x^{*}$.

Now, we show that $x^{*}$ is the unique fixed point of T. Assume that $x^{\prime}$ is an other fixed point of T. Then, we have $. T x^{\prime}=x^{\prime}$. and

$$
\begin{aligned}
d\left(x^{*}, x^{\prime}\right) & =d\left(T x^{*}, T x^{\prime}\right) \\
& \leq \lambda\left[d\left(x^{*}, T x^{\prime}\right)+d\left(x^{\prime}, T x^{*}\right)\right]
\end{aligned}
$$

From (2.18), we obtain $d\left(x^{*}, x^{\prime}\right) \leq 2 \lambda d\left(x^{*}, x^{\prime}\right)$. This implies that $x^{\prime}=x_{0}$. This completes the proof.

Remark 6. The headlights from Theorem 2, we needed a restriction to valid Chatterjea's fixed point theorem in $b$ metric space.

\section{References}

[1] Choudhury, B. S., Unique fixed point theorem for weakly ccontractive mappings, Kathmandu Univ. J. Sci, Eng and Tech, 5 (1),2009, 6-13.

[2] Kannan, R, Some results on fixed points, Bull. Calcutta Math Soc., 60, 1968, 71-76.

[3] Chatterjea, S. K, Fixed point theorems, C.R. Acad. Bulgare Sci. 25, 1972, 727-730.

[4] Czerwik, S., Contraction mappings in b-metric spaces, Acta Math inf Univ Ostraviensis. 1 (1993), 5-11.

[5] Czerwik, S., Nonlinear set-valued contration mappings in $b$-metric spaces, Atti Sem Math Fis Univ Modena. 46(2), (1998), 263-276.

[6] Boriceanu, M., Fixed point theory for multivalued generalized contraction on a set with two b-metrics, Studia Univ Babes-Bolyai Math. LIV (3), (2009),1-14.

[7] Aydi et al., A fixed point theorem for set valued quasicontractions in $b$-metric spaces, Fixed Point Theory and Applications, 2012 2012:88.

[8] Berinde, V., Iterative Approximation of Fixed Points, Springer, (2006). 